\title{
QN \\ Vacinas e Covid-i9: Qual, Como, Quando e em Quem? Medicina, Mercado, Política E SOCIEDADE
}

\section{Vacinas CONTRa Covid}

Imagine ter a disposiçáo uma variedade de imunizantes contra covid-19. E aí, qual a melhor opção para vacinação em massa e para vacinar grupos específicos? Estas perguntas mobilizaram cerca de 350 participantes durante o simpósio "Vacinas e covid-19: Qual, quando, como, em quem? Medicina, mercado, política e sociedade", promovido por um consórcio que reuniu as Academias Nacional de Medicina (ANM), Brasileira de Ciências $(\mathrm{ABC})$ e de Ciências Farmacêuticas do Brasil (ACFB), e realizado na última quinta (17).

Para quem anseia por uma vacina contra covid-19, o Secretário de Relações Exteriores da Academia Nacional de Medicina dos Estados Unidos, Carlos del Rio, lembrou alguns exemplos de desenvolvimento de vacinas que levaram cerca de 30 anos: contra a varicela foram 28 anos. Outros 15 anos foram necessários para desenvolvimento tanto $\mathrm{da}$ vacinas contra o HPV, como para o rotavirus. E pesquisadores do mundo todo sonham em desenvolver uma vacina contra covid em apenas 18 meses. Será possível?
A brasileira Mariângela Simão, atualmente na Organizaçáo Mundial da Saúde, sentenciou que essa pandemia não é uma corrida de $1000 \mathrm{~m}$. É uma maratona! Num otimismo cauteloso, segundo ela, a OMS estima que a vacina contra a covid-19 ficará pronta até meados de 2021, mas possivelmente, só haverá vacina para cerca de $20 \%$ da populaçáo. Com isso, será necessário eleger os grupos essenciais que receberão o imunizante $\mathrm{e}$ incorporar ao cotidiano medidas preventivas como o uso de máscaras, distanciamento social, lavagem das mãos ou uso de álcool em gel.

Imunizantes - Uma das questóes importante abordadas por um dos coordenadores do evento, o pesquisador Jorge Kalil (ABC), e ainda sem resposta é quão prolongada será a resposta imunológica à vacina. Segundo ele, ainda não se sabe, mas todos os grupos estáo tentando estudar as células de memória e fazer uma projeçấo. Alguns apontam que os anticorpos se mantêm, "mas não sabemos se os anticorpos são suficientes para manter a imunidade. Talvez, seja necessária também uma resposta celular", afirmou. 
Além disso, Kalil comentou sobre as perspectivas da vacina acabar realmente com o vírus (esterilizante) ou só evitar que os indivíduos desenvolvam a forma grave da doença. Isso, segundo ele, poderá ter impacto na saúde pública, pois os indivíduos não terão a doença, mas continuarão a disseminar o vírus.

Vacinas por RNA, DNA, vetores virais, adenovirus de chipanzé e baseadas em proteínas foram ainda apresentadas e discutidas por vários convidados durante o evento.

A pesquisadora Lily Yin Weckx, da Unifesp, e Maria Bernardini, diretora médica da Astra Zeneca, esclareceram por que o país desperta o interesse de vários grupos internacionais para testes de vacina, destacando a excelência dos grupos de pesquisadores brasileiros e o número de infectados no país. Lily Yin mostrou como é a composição da vacina de Oxford que utiliza vetores virais modificados de chipanzé, onde se insere a proteína do SARS-CoV-2, o que desecadeará uma resposta imune.

Entre outras iniciativas apresentadas, as estratégias da GlaxoSmithKline que visa uma vacinação em massa. Segundo o presidente José Carlos Felner, a empresa pretende lançar apenas no fim de 2021 a melhor solução de imunizante, que inclua a distribuição e que atinja ao maior número de pessoas.

Outro convidado do evento foi o pesquisador Esper Kallás, da USP, que contou sobre a iniciativa dos testes com a vacina Coronavac, do Butantan/Sinovac, conhecida como a vacina chinesa.Cerca de 4.700 voluntários no São Paulo, Rio de Janeiro, Minas Gerais, Paraná e Rio Grande do Sul estão participando dos testes que tem uma projeção de atingir um total 8.870 voluntários.

A epidemiologista Carla Domingues, outra palestrante do evento, ressaltou a excelência do Programa Brasileiro de Imunizações, mas alertou que o Ministério da Saúde precisa pensar na logística da vacinação para covi-19. Como será a vacinação, por exemplo, nas cidades ribeirinhas, onde o acesso é feito por barcos, caso a vacina necessite de refrigeração? Teremos seringas e agulhas suficientes para vacinar a população?, questionou Domingues.

O presidente da ANM, Rubens Belfort, ressaltou ao longo do simpósio a importância da boa evidência científica e da comunicação eficaz junto à sociedade para evitar a politização da vacinação.

- Se por um lado, defendemos a evidência científica, somos os primeiros a admitir que elas são, às vezes, transitórias. Dizem que a medicina é um conjunto de ideias passageiras, transformadas em leis por questóes didáticas e comerciais. $\mathrm{E}$ as vacinas também estão nessa área. Por isso, temos que ter muita responsabilidade para explicar que as evidências, às vezes, ainda são frágeis e, principalmente, mudam com o tempo.

$\mathrm{O}$ assunto foi reforçado pelo presidente da Academia Brasileira de Ciências, Luiz 
Davidovich. Segundo ele, a ciência não tem verdades. Ela busca a verdade. Se tivesse verdades permanentes, não seria ciência. Precisamos estar atentos ao interesse do público, pois temos grande responsabilidade de transmitir os avanços e processos científicos de forma clara e mostrar que o tempo da ciência é diferente do tempo dos políticos.

O jornalista e ex-Governador do Rio Grande do Sul, Antonio Britto, complementou as reflexões e preocupações. Ele interrogou quem estará no comando da imunização? A vacinação não pode ser palco de disputas ideológicas e corrupção como assistimos em várias cidades do país durante a pandemia de covid-19, enfatizou. O diretor da BandNews, Marcello D'Angelo, somou a essa preocupação:

- Na pandemia por covid-19, assistimos perplexos muitos casos de desvio de conduta em diversos governos estaduais, como os episódios no Rio de Janeiro, Santa Catarina e outras cidades. Também acompanhamos as disputas de vários países por máscaras, respiradores e outros equipamentos. E, infelizmente, estas negociações tiveram interferências políticas que mudaram os rumos de aquisição dos insumos. Essa situação não pode se repetir com a vacina, disse D'Angelo.

Participaram ainda dos debates, os acadêmicos da ANM, Celso Ferreira e Marcelo Morales, representando o Ministério da Ciência, Tecnologia e Inovação, que falou sobre os investimentos governamentais; os acadêmico da ABC, Ricardo Gazinelli; Marco Antonio Stephano e Nelson Mussolini, da Academia de Ciências Farmacêuticas do Brasil.

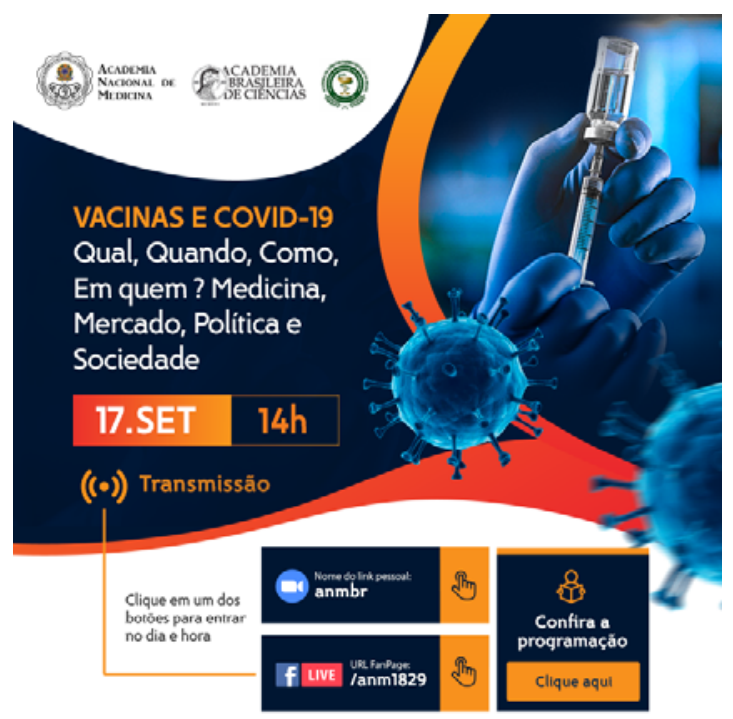

PROGRAMAÇĀO
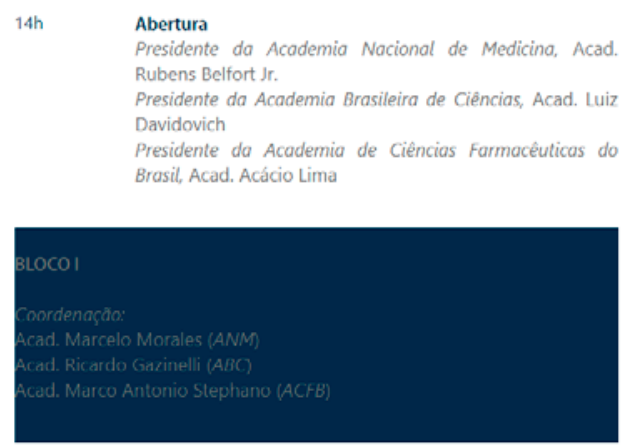

14h10 Vacinas CoviD Brasil 5 min cada

Acad. Marcelo Morales (ANM)

Acad. Ricardo Gazzinelli (ABC)

Acad. Jorge Kalil (ABC)

Acad. Celso Ramos (ANM)

\begin{tabular}{ll}
$14 h 30 \quad$ Discussão \\
\hline 14 h40 & $\begin{array}{l}\text { Iniciativas da OMS para oferecer vacinas com equidade } \\
\text { Profa. Dra. Mariângela Simão (Organizaçõo Mundial da } \\
\text { Sacide - OMS) }\end{array}$
\end{tabular}




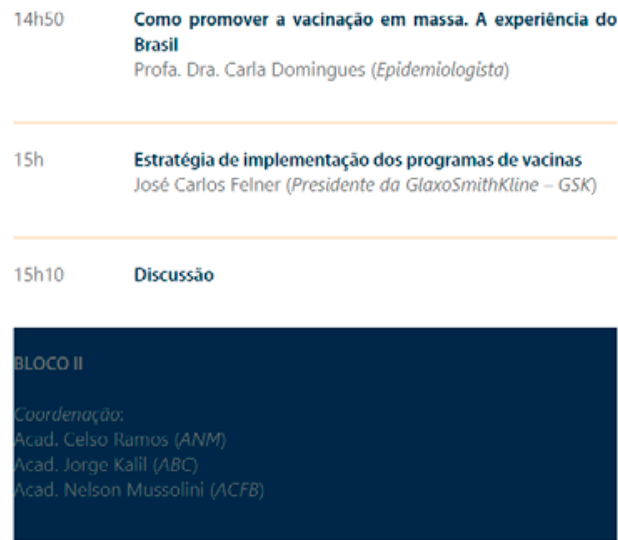

15 h20 Testes clínicos de fase 3 da vacina AzD-1222 no Brasil (Vacinas Oxford)

Profa. Dra. Lily Yin Weckx (Unifesp)

15 Provável disponibilidade da vacina no Brasil
Dra. Maria Bernardini (Diretora Médica, Astra Zeneca)

15 h40 "Vacina Coronavac do Butantan/Sinovac"

Prof. Dr. Esper Georges Kallás (USP)

Vacina Russa - TecPar
Prof. Dr. Jorge Augusto Callado Afonso (Presidente do
Instituto de Tecnologia do Paraná - TECPAR)

\begin{tabular}{ll}
$16 \mathrm{~h}$ & $\begin{array}{l}\text { As Expectativas da Sociedade } 15 \text { min cada } \\
\text { Antonio Brito (ex-Governador do Rio Grande do Sul) } \\
\text { Marcello D'Angelo (Diretor Band News) } \\
\text { Pedro Thompson (Presidente da Plataforma Exame) }\end{array}$ \\
\hline $16 \mathrm{~h} 45 \quad$ Discussă。 \\
\hline $17 \mathrm{~h} 30$ & Intervalo
\end{tabular}

\section{SESSAO ORDINARIA DA ACADEMIA NACIONAL DE MEDICINA} XXVIII - ANO ACADEMICO 191

\begin{tabular}{ll}
$18 \mathrm{~h}$ & $\begin{array}{l}\text { Abertura } \\
\text { Presidente da Academia Nacional de Medicina, Acad. } \\
\text { Rubens Belfort Jr. }\end{array}$ \\
$18 \mathrm{~h} 05$ & $\begin{array}{l}\text { Comunicaçōes da Secretaria Geral } \\
\text { Acad. Ricardo Cruz }\end{array}$ \\
\hline $10 h 15$
\end{tabular}

\begin{tabular}{l} 
18h25 $\begin{array}{l}\text { Challenges of developing and deploying a vaccine during a } \\
\text { pandemic } \\
\text { Carlos Del Rio, MD, PhD } \\
\text { Secretário de Relaçōes Exteriores da National Academy of } \\
\text { Medicine - EUA }\end{array}$ \\
\hline $19 \mathrm{~h} \quad$ Mesa Redonda e Discussāo com a Bancada Acadêmica \\
\hline $20 \mathrm{~h} \quad$ Encerramento
\end{tabular}

Para assistir na integra aos vídeos desse Simpósio, basta abrir esse QR Code abaixo em seu celular ou tablet.

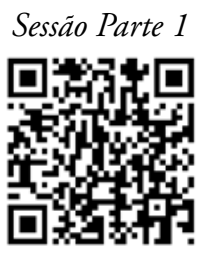

Sessão Parte 2

Todas as Sessóes
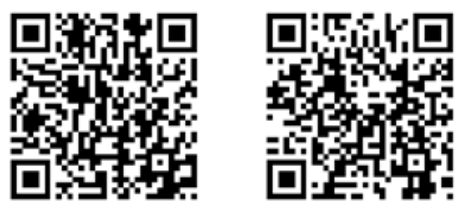

Comunicaçōes dos Acadêmicos 